\title{
Trait and abundance patterns in two marine molluscs: the influence of abiotic conditions operating across multiple spatial scales
}

\author{
Hannah B. Lloyd*, Brad R. Murray, Paul E. Gribben \\ Plant Functional Biology and Climate Change Cluster, School of the Environment, University of Technology Sydney, \\ Broadway, New South Wales 2007, Australia
}

\begin{abstract}
Theoretical mechanisms describing species abundance distributions should also underpin geographic variation in life-history traits. However, recent studies suggest that abundance and trait patterns may not co-vary and may respond differently to abiotic conditions acting at different spatial scales. We examined patterns in abundance and body size of 2 estuarine molluscs, the arkshell Anadara trapezia and the mudsnail Batillaria australis, across their wide distributions in eastern Australia. We related abundance and body size patterns to abiotic variables including water temperature, $\mathrm{pH}$, salinity, sediment redox and dissolved oxygen content at multiple spatial scales. Two hypotheses were tested: (1) geographic patterns in abundance and body size do not co-vary, and (2) patterns in abundance are more strongly influenced by abiotic conditions occurring at a large spatial scale (e.g. across latitudinal gradients) whereas body size is more strongly influenced by variation in abiotic conditions occurring at smaller scales. The influence of spatial scale and associated abiotic variables on abundance and body size distributions was determined using multiple linear regression, ANOVA and variance component analyses. Geographic variation in abundance and body size were independent of each other in both species. Abiotic variation across latitudinal gradients was the strongest predictor of abundance, but factors that varied substantially at local scales (e.g. dissolved oxygen and sediment redox) were the strongest predictors of body size. Our data indicate that geographic patterns in body size and abundance can be disconnected from each other, most likely due to differential responses to abiotic variation acting at different spatial scales.
\end{abstract}

KEY WORDS: Biogeography $\cdot$ Spatial scale $\cdot$ Abiotic variation $\cdot$ Abundance $\cdot$ Body size $\cdot$ Anadara trapezia $\cdot$ Batillaria australis

\section{INTRODUCTION}

Although biogeographic theory explains variation in the abundance and life-history traits of species over broad spatial scales (e.g. Bergmann's Rule and the abundant-centre hypothesis), individual species often do not conform to predicted patterns (see Sagarin \& Gaines 2002, Meiri \& Dayan 2003). Indeed, recent studies show that the traits and abundance of some species are more variable at local compared to broad spatial scales (e.g. Gilman 2005, Messier et al. 2010, Tam \& Scrosati 2011). Sagarin \& Gaines (2002) suggest that a lack of generality in regard to species distribution patterns may be due to the dominant forces at local scales masking expected patterns at large scales. Despite this, broad and local scale research approaches remain largely independent of each other. Determining which scales explain most of the variation in traits and abundance may help to reconcile why some species do not conform to biogeographical predictions (Messier et al. 2010), and focus research efforts on patterns and processes at spatiotemporal scales that are ecologically most important (McGill 2008). 
Recent studies that have simultaneously determined trait and abundance patterns indicate that each may respond differently to spatially distributed abiotic variables. This contrasts with theory suggesting that the factors underlying species abundance distributions should also influence geographic variation in life-history traits (Rivadeneira et al. 2010). For example, for 3 mussel species on the northwest Atlantic coast of the USA, there is a negative relationship between abundance and abiotic stress acting at large spatial scales (Tam \& Scrosati 2011). In contrast, traits of the mussels such as body size and age are regulated more by local conditions. The size of the limpet Collisella scabra is more strongly influenced by microhabitat and is less variable at large spatial scales, in contrast to patterns of abundance (Gilman 2005). We therefore make 2 predictions: (1) patterns of abundance and traits are disconnected and (2) the geographic distribution of abundance is more strongly influenced by large-scale abiotic processes, while life-history traits are influenced more by abiotic processes acting at small spatial scales. We suggest that much is to be gained by understanding not only how abundance and traits vary over multiple spatial scales, but also how they respond to variation in abiotic conditions over the same spatial scales. Indeed, several authors highlight the need for a more integrated framework for understanding patterns in species abundance and life-history traits (e.g. Sagarin et al. 2006, Rivadeneira et al. 2010).

In this study, we examined patterns in abundance and body size of 2 estuarine marine molluscs, the arkshell Anadara trapezia (Deshayes 1840) and the mudsnail Batillaria australis (Quoy and Gaimard 1834), across their geographic distributions in eastern Australia. Specifically, we related abundance and body size patterns in each species to abiotic variables including water temperature, $\mathrm{pH}$, salinity, sediment redox and dissolved oxygen content at multiple spatial scales. These scales included a broad latitudinal gradient (often used as a proxy for large scale abiotic change), sites within locations and 2 contrasting habitat types (seagrass vs. unvegetated sediments). For both species, we tested the hypotheses that (1) geographic patterns in abundance and body size do not co-vary, and (2) patterns in abundance are more strongly influenced by abiotic conditions occurring at a large spatial scale (e.g. variation along the latitudinal gradient) compared with patterns in life-history traits, which are more strongly influenced by variation in abiotic conditions occurring at smaller spatial scales (e.g. among sites and between the 2 local habitat types).

\section{MATERIALS AND METHODS}

\section{Study species}

Anadara trapezia is a thick-shelled suspensionfeeding bivalve (max. shell length $75 \mathrm{~mm}$ ) (Edgar 1997, Wright \& Gribben 2008). Batillaria australis is a deposit-feeding marine gastropod (max. length $45 \mathrm{~mm}$ ) (Edgar 1997). Both A. trapezia and B. australis are often the dominant marine molluscs in estuarine waters, co-occurring in seagrass and unvegetated habitats from Southern Queensland to Victoria (Edgar 1997, Gribben et al. 2009b, McKinnon et al. 2009). Both species occur from the intertidal to shallow subtidal regions (max. depth $\sim 4 \mathrm{~m}$ ) (Edgar 1997).

Anadara trapezia and Batillaria australis are ideal organisms with which to address our hypotheses for several reasons: (1) they co-occur and are broadly distributed over $1400 \mathrm{~km}$ of near-linear coastline (Edgar 1997), allowing us to easily test for geographic patterns in abundance and body size (Gilman 2005, Rivadeneira et al. 2010, Tam \& Scrosati 2011). (2) Body size and abundance differ between the 2 habitat types in which the species occur, i.e. seagrass and unvegetated sediments (Wright et al. 2007, Wright \& Gribben 2008, Gribben et al. 2009b). This allows exploration of latitudinal patterns in body size and abundance in 2 contrasting local habitats throughout the distributions of the species. Few studies have considered whether geographic patterns of abundance and traits are consistent among habitats for species that occur in multiple habitats (but see Gilman 2005). (3) Body size and abundance of these species respond strongly to abiotic conditions (e.g. water column dissolved oxygen and sediment anoxia), which vary over local spatial scales (i.e. between sites and among estuaries), allowing us to investigate multiple relevant abiotic variables that act at small and large spatial scales (Gribben et al. 2009b, McKinnon et al. 2009, Wright et al. 2010).

\section{Study sites}

Abundance and body size of Anadara trapezia and Batillaria australis were measured in co-occurring seagrass and unvegetated habitats at multiple locations over the latitudinal distribution of A. trapezia along the east coast of Australia (Edgar 1997, OZCAM 2010). This also covered $\sim 80 \%$ of the distribution of $B$. australis. The study area ranged from Gladstone, Queensland to Merimbula, New South Wales, spanning $\sim 1457 \mathrm{~km}$ and 12.9328 degrees of 
latitude (Fig. 1). At each location, 2 sites (each containing both seagrass and unvegetated habitats) separated by at least $1 \mathrm{~km}$ were sampled. Sampling was conducted predominantly in summer from late November 2009 to early February 2010. Sites were sampled haphazardly to minimise any confounding temporal effects. At Gladstone, the northernmost location of $A$. trapezia, only 1 site and 1 habitat (unvegetated sediment) were surveyed as there was no seagrass present, and study sites were limited because of industrial use in the area $(H$. B. Lloyd pers. obs.).

\section{Data collection}

Sampling of both species was conducted in intermingling patches of seagrass and unvegetated sediments throughout a 0.2 to $1.5 \mathrm{~m}$ depth range at all sites to incorporate potential spatially confounding effects (e.g. changes in shell length and abundance with depth) (Malcolm et al. 2009). Abundances of both species were recorded in 15 haphazardly placed quadrats in each habitat. Different quadrat sizes for each species were used (Anadara trapezia, $50 \times 50 \mathrm{~cm}$; Batillaria australis, $25 \times 25 \mathrm{~cm}$ ) because of the high abundance of $B$. australis at some sites. All data were converted to number of individuals $\mathrm{m}^{-2}$ prior to statistical analysis. Seagrass quadrats were only placed in the native seagrass Zostera capricorni in areas with $>90 \%$ cover. Quadrats in unvegetated sediments were only sampled in plots $100 \%$ bare of seagrass and other macrophytes. Individuals were counted by hand, digging to a depth of $\sim 10 \mathrm{~cm}$. Hand searches for A. trapezia have been used successfully in other studies (Wright \& Gribben 2008, McKinnon et al. 2009).

To measure body size, individuals of both species were haphazardly collected from both habitats (Anadara trapezia, $\mathrm{n}=50$ habitat $^{-1}$ site $^{-1}$; Batillaria australis, $\mathrm{n}=16-50$ habitat $^{-1}$ site $^{-1}$ ). To ensure body size patterns were not biased by the presence of small recruits, only mature individuals were sampled (A. trapezia, $>15 \mathrm{~mm} ;$ B. australis, $>10 \mathrm{~mm}$ ). No individuals of $B$. australis were found at Merimbula (Location 6) or in unvegetated sediments at $\mathrm{St}$ Georges Basin (Location 5) (see Figs. 2 \& 3). Once collected, molluscs were transported to the laboratory at the University of Technology Sydney. In the laboratory, shell length of all individuals was determined using Vernier callipers (after Wright \& Gribben 2008, Gribben et al. 2009b). Shell length was used as a measure of body size as morphological

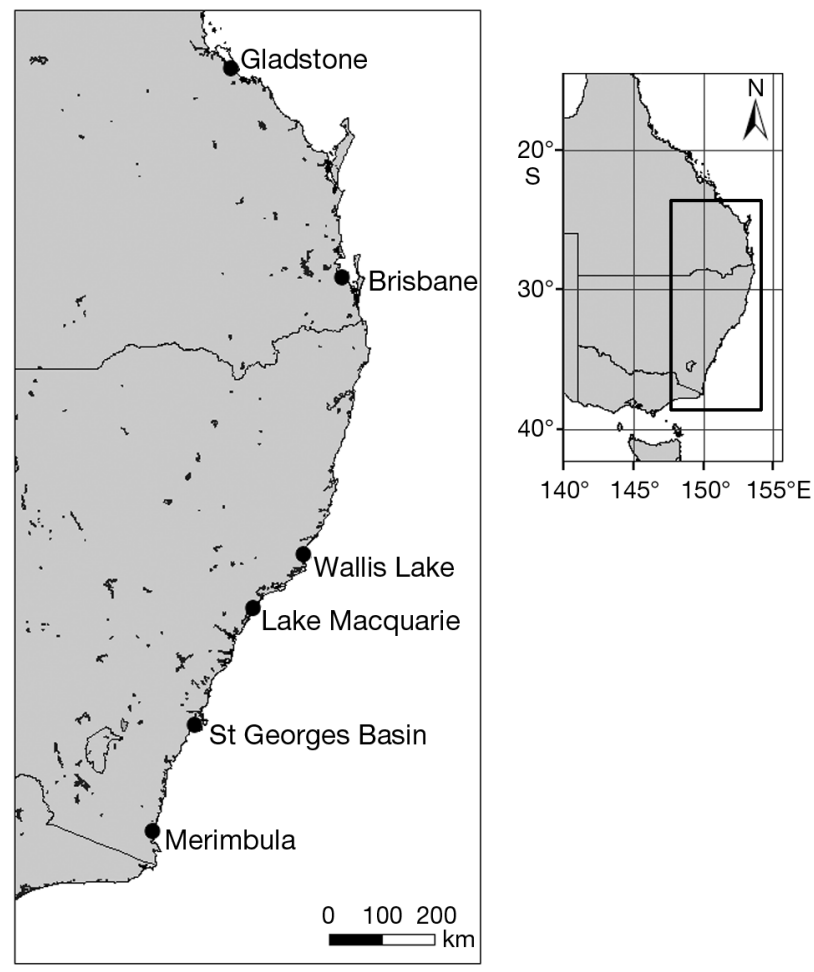

Fig. 1. Study area along the east coast of Australia, showing (north to south) Location 1 in Gladstone to Location 6 in Merimbula

traits (e.g. length, width, height, total weight) are highly correlated in marine molluscs such as $A$. trapezia (Wright \& Gribben 2008, Gribben et al. 2009a, Wright et al. 2012).

To investigate the effects of abiotic variation on the abundance and body size of Anadara trapezia and Batillaria australis, water temperature, $\mathrm{pH}$, salinity, dissolved oxygen (DO) and sediment redox (a proxy for general sediment health) (Gribben et al. 2009b, McKinnon et al. 2009, Wright et al. 2010) were measured in all habitats at all sites. All these abiotic variables can have important effects on marine invertebrates (Rainer et al. 1979, Berge et al. 2006, Harley et al. 2006, Bibby et al. 2007, Gribben et al. 2009b, McKinnon et al. 2009, Wright et al. 2010). Environmental sampling was concurrent with abundance and animal collection at each site. Measures of all variables were taken from replicate intermingling patches of habitats $(\mathrm{n}=5$ patches habitat $^{-1}$ site $^{-1}$ ). Water measurements (temperature, $\mathrm{pH}$, salinity, DO) were taken at approx. $5 \mathrm{~cm}$ above the benthos in each habitat (Gribben et al. 2009a). Water temperature and DO were measured using an Oxi 330i meter, $\mathrm{pH}$ was measured using a $\mathrm{pH}$ 330 meter and salinity was measured using a Cond 
330i meter. Redox was measured in sediment cores (diameter $50 \mathrm{~mm}$, length $100 \mathrm{~mm}$ ) from both habitats. The redox 330i probe was inserted to a depth of $1 \mathrm{~cm}$ into the top of the core (Gribben et al. 2009b, McKinnon et al. 2009). All meters were recalibrated at each site in accordance with the manufacturer's instructions (WTW).

\section{Data analysis}

Co-variance in body size and abundance

Spatial correlation was used to explore the relationship between body size and abundance patterns, using Spatial Analysis in Macroecology (SAM v. 4.0). Co-variance between body size and abundance was investigated using Pearson's correlation coefficients that were adjusted to account for the spatial autocorrelation procedure. Because abundance data were based on individuals within quadrats and size data were based on individuals within each habitat, data were converted to mean abundance $\mathrm{m}^{-2}$ within each habitat at each site, and mean shell length within each habitat at each site, respectively.

\section{Abiotic contribution}

Separate linear regression models were built using Akaike's Information Criterion (AIC) (SAM 4.0) to determine which abiotic factors (latitude, water temperature, pH, salinity, DO and redox) explained significant variation in the abundance and body size of each species. The AIC excluded variables that did not contribute to the model. For both species, abundance data were log-transformed to meet assumptions of normality and homogeneity of variances. Moran's I was calculated from the regression residuals to determine the effect of spatial autocorrelation on neighbouring sites. Spatial autocorrelation in neighbouring sites can increase the chance of Type I error resulting from non-independence of the model residuals (Rangel et al. 2010).

\section{Effect of spatial scale}

Three-factor nested ANOVAs were used to further explore the importance of the factors habitat (fixed factor), sites within locations (nested, random factor) and locations (random factor) on abundance and body size for each species (JMPIN v.4). For abun- dance, where interaction terms were significant, Student-Newman-Keuls (SNK) tests were used to test for differences among locations within habitats separately, and differences between habitats within each location. Because our target species only occurred at 1 habitat at some sites, we forced a balanced design to provide a stronger test of the influence of habitat, our smallest spatial scale. For Anadara trapezia, Location 1 was excluded from abundance and body size analyses. For Batillaria australis, Locations 1 (Gladstone), 5 (St Georges Basin) and 6 (Merimbula) were excluded from analysis.

We conducted variance component analyses to investigate the spatial scales that explained the most variation in the abundance and size of both species. The models and factors included were the same as described above for the nested ANOVAs. Note that there is no variance component for the fixed factor 'habitat', only for the random factors, their interactions, and the interactions between habitat and site (location) and habitat and location (Underwood 1997, Quinn \& Keough 2002). Where interactions were significant, variance components were determined for each habitat separately.

\section{RESULTS}

\section{Co-variance in body size and abundance}

The mean abundance $\pm \mathrm{SE}$ of Anadara trapezia ranged from $2.9 \pm 0.61$ ind. $\mathrm{m}^{-2}$ in unvegetated habitat at Gladstone to $163.5 \pm 24.2$ ind. $\mathrm{m}^{-2}$ in seagrass at Merimbula (Fig. 2a). For Batillaria australis, mean abundance ranged from 0 ind. $\mathrm{m}^{-2}$ (recorded at both sites in Merimbula and unvegetated habitat in St Georges Basin) to $641 \pm 96.6$ ind. $\mathrm{m}^{-2}$ in seagrass at Lake Macquarie (Fig. 2b). A. trapezia shell length ranged from 15 to $68 \mathrm{~mm}$ in unvegetated sediments at Brisbane and at Wallis Lake, respectively (Fig. 3a). $B$. australis shell length ranged from 12.5 to $48 \mathrm{~mm}$ in seagrass at Lake Macquarie and unvegetated sediments at Brisbane, respectively (Fig. 3b).

For Anadara trapezia there was no correlation between body size and abundance in either seagrass (Pearson correlation, $r=0.241, \mathrm{p}=0.478$ ) or unvegetated habitats $(r=0.219, p=0.496)$, or for both habitats combined ( $\mathrm{r}=0.061, \mathrm{p}=0.789$ ). For Batillaria australis there was also no correlation between body size and abundance in either seagrass ( $\mathrm{r}=0.026, \mathrm{p}=0.951$ ) or unvegetated habitats $(\mathrm{r}=-0.462, \mathrm{p}=0.258)$, or in both habitats combined $(\mathrm{r}=-0.123, \mathrm{p}=0.662)$. 


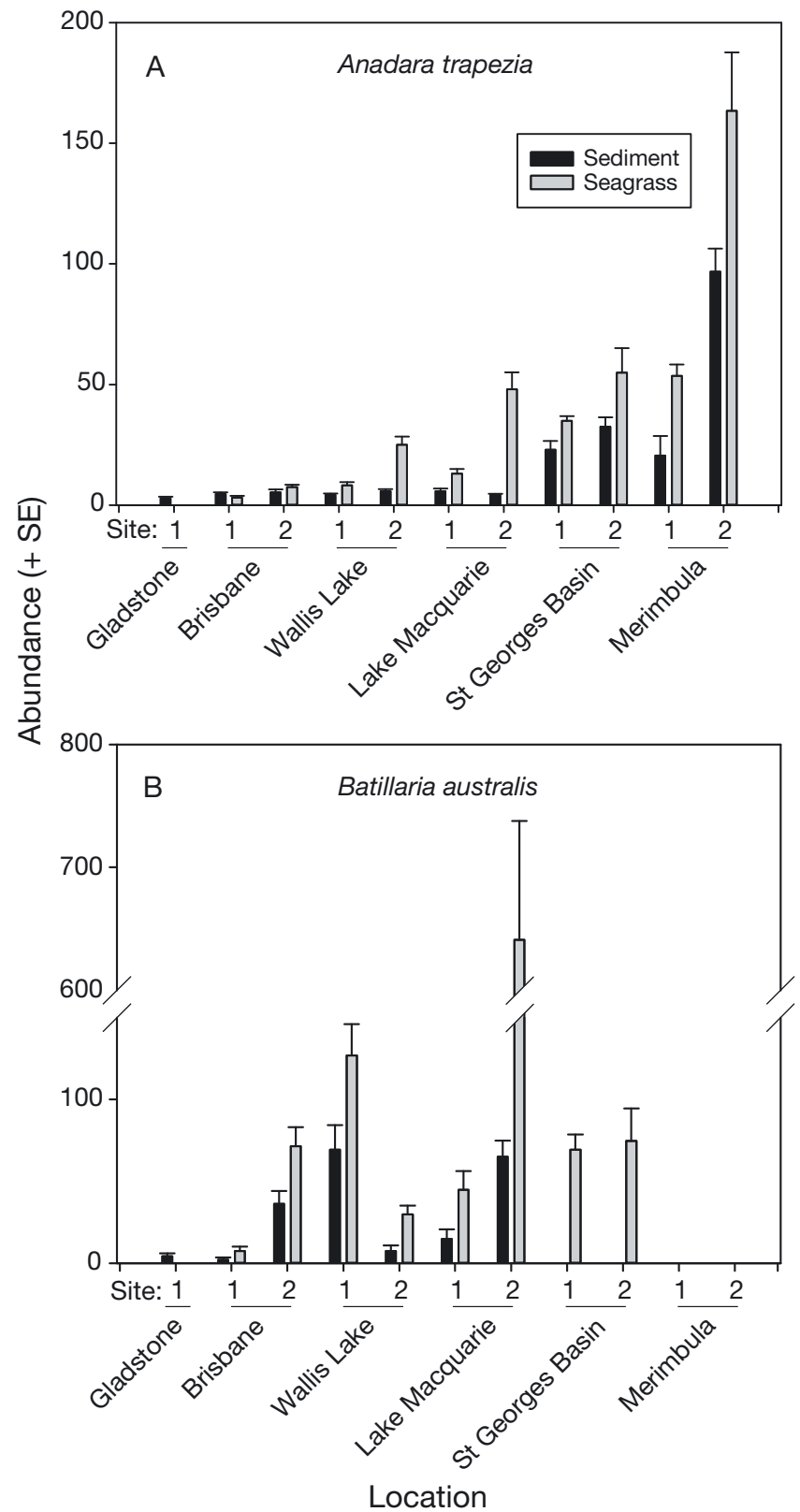

Fig. 2. Mean + SE abundance of Anadara trapezia and Batillaria australis in unvegetated sediment and seagrass habitats at 2 sites (except Gladstone) in each of 6 locations on the east coast of Australia ( $n=15$ replicate quadrats habitat ${ }^{-1}$ site $^{-1}$ )

\section{Abiotic contribution}

For Anadara trapezia, latitude was the only significant factor $(\mathrm{p}=0.002)$ determining abundance, and the final model excluded all variables except latitude and temperature $\left(\mathrm{r}^{2}{ }_{\text {adj }}=63.5\right)$. For Batillaria australis, latitude was the strongest predictor of abundance $(p=0.08)$ and the only factor included in the final model. The model for A. trapezia shell length in-
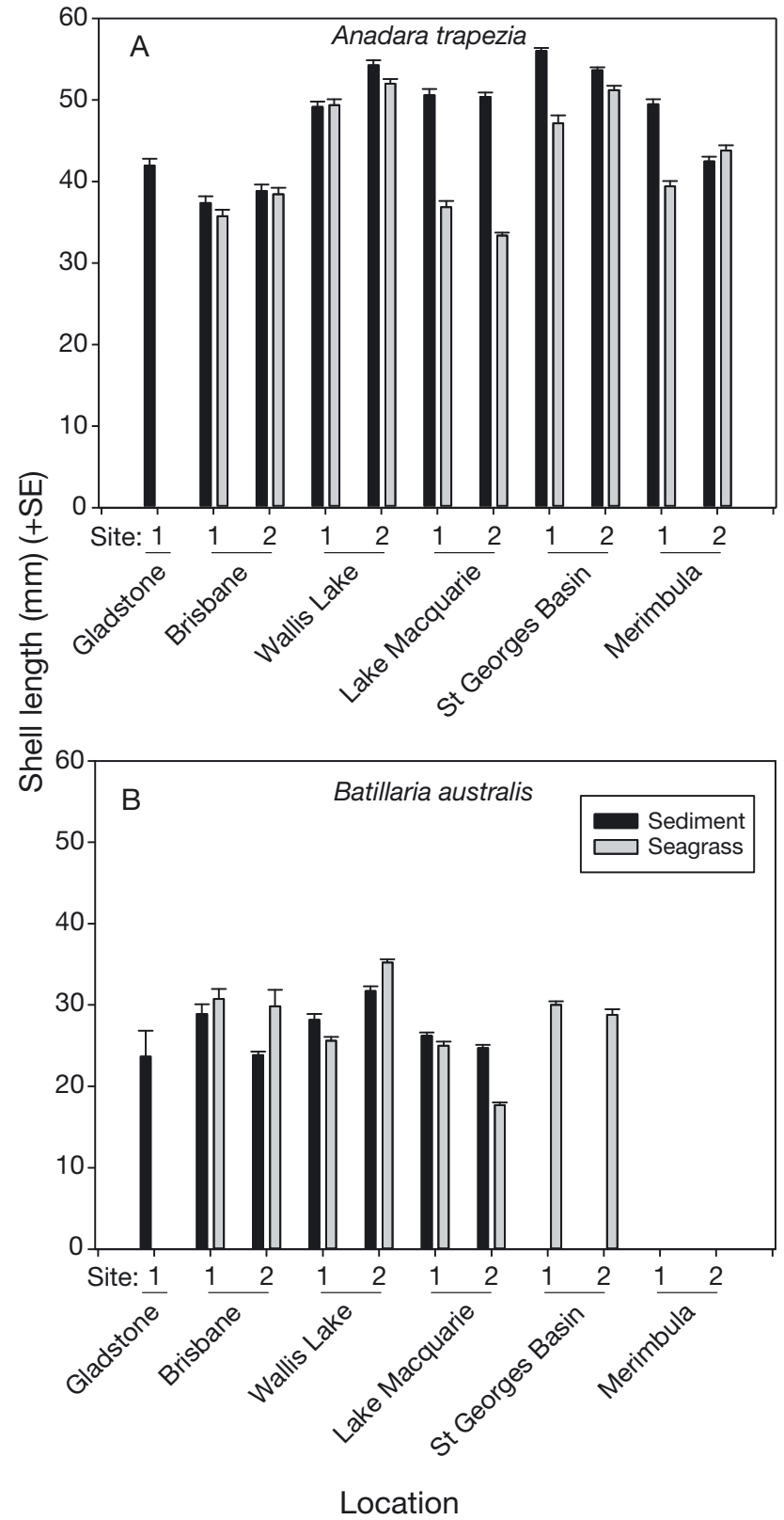

Fig. 3. Mean + SE body size (shell length) of Anadara trapezia and Batillaria australis in unvegetated sediment and seagrass habitats at 2 sites in each of 6 locations on the east coast of Australia ( $n=50$ ind. habitat ${ }^{-1}$ site $^{-1}$ for A. trapezia; $\mathrm{n}=16$ to 50 ind. habitat ${ }^{-1}$ site $^{-1}$ for $B$. australis)

cluded the significant predictors latitude $(\mathrm{p}<0.001)$, DO $(\mathrm{p}<0.001)$, and redox $(\mathrm{p}=0.022)\left(\mathrm{r}^{2}{ }_{\mathrm{adj}}=0.619\right)$. For $B$. australis shell length, the final model included DO $(p=0.008)$ and redox $(p=0.57)\left(r^{2}{ }_{a d j}=0.464\right)$. For all the models, the Moran's $I$ for the regression residuals showed negative autocorrelation in the first distance class, discounting the issue of dependence and Type I error (Rangel et al. 2010). As autocorrelation 
presented no issues in the analyses it is not discussed further.

\section{Effect of spatial scale}

For Anadara trapezia, all 3 spatial scales contributed to observed patterns of abundance. There was a significant interaction between habitat and site (location) (Fig. 2a, Table 1). For seagrass, abundances were significantly lower in Brisbane compared to all other locations, which were not significantly different (all SNK tests $p<0.05$ ). In unvegetated sediments, the 2 southern locations (St Georges Basin and Merimbula) had significantly higher abundances than the 3 northern locations (Brisbane, Wallis Lake and Lake Macquarie) (all SNK tests $\mathrm{p}<0.05)$. There were no differences in abundance within the 2 groupings (all SNK tests $\mathrm{p}>0.05$ ). In both habitats there was a general increase in abundance polewards. Within locations, abundances were highly variable between sites. The abundance of A. trapezia was generally higher in seagrass compared to unvegetated sediment at all locations, although differences were only significant at Lake Macquarie (Location 4) (SNK p < 0.05). Although all

Table 1. Nested ANOVA testing the effect of location (random factor), habitat (fixed factor) and site (nested within location; random factor) on the abundance of Anadara trapezia and Batillaria australis (ind. $\mathrm{m}^{-2}$ ) in unvegetated sediment and seagrass habitats from 2 sites from multiple locations (5 for $A$. trapezia and 3 for $B$. australis) on the east coast of Australia. Abundance data were log-transformed. $\mathrm{n}=15$ quadrats habitat ${ }^{-1}$ site $^{-1}$ species $^{-1}$. Significant effects $(p<0.05)$ are highlighted in bold

\begin{tabular}{|lrrcc|}
\hline Source & df & \multicolumn{1}{c}{ MS } & $F$ & $\mathrm{p}$ \\
\hline A. trapezia & & & & \\
Habitat & 1 & 55.098 & 4.655 & 0.097 \\
Site (Location) & 5 & 15.276 & 2.845 & 0.138 \\
Location & 4 & 97.084 & 4.465 & 0.060 \\
Location $\times$ Habitat & 4 & 11.204 & 2.204 & 0.204 \\
Habitat $\times$ Site (Location) & 5 & 5.370 & 2.367 & $\mathbf{0 . 0 4 0}$ \\
Residual & 280 & 2.269 & & \\
Student-Newman-Keuls tests: & & & \\
Sediment abundance: Location $2=3=4<5=6$ & \\
Seagrass abundance: Location $2<3=4=5=6$ & \\
B. australis & & & & \\
Habitat & 1 & 78.374 & 59.953 & $\mathbf{0 . 0 1 6}$ \\
Site (Location) & 3 & 164.024 & 54.675 & $\mathbf{0 . 0 1 9}$ \\
Location & 2 & 24.537 & 0.462 & 0.670 \\
Location $\times$ Habitat & 2 & 1.307 & 0.451 & 0.674 \\
Habitat $\times$ Site (Location) & 3 & 2.897 & 1.998 & 0.116 \\
Residual & 168 & 1.450 & & \\
\hline
\end{tabular}

variance components were non-significant, for both habitats, location explained more than twice the variation in abundance compared to site (location), supporting the results of the regression analysis which indicated that factors acting at large spatial scales (i.e. latitude) were the most important predictors of abundance (Table 2).

For Batillaria australis, the 2 smallest spatial scales, habitat and site, had a significant effect on abundance (Fig. 2b, Table 1). Abundances were higher in seagrass compared to unvegetated sediments, but did not differ among locations, although they were highest in the central locations. We could not interpret the negative variance components (Table 2).

The shell length of Anadara trapezia showed an interaction between habitat and site (location) (Fig. 3a, Table 3). Shell length was significantly greater in seagrass habitat in 2 central locations (Wallis Lake and St Georges Basin, Locations 3 and 5 , respectively) (both SNK tests $\mathrm{p}<0.05$ ) compared to the remaining locations. There were no significant differences in shell length in unvegetated sediments among locations (all SNK tests $\mathrm{p}>0.05$ ). There were no significant differences in shell length between habitats within locations (all SNK tests $\mathrm{p}>$ 0.05), although mean shell length was greater in unvegetated sediments than in seagrass at all locations. For the variance component analyses, only the habitat $\times$ site (location) interaction (i.e. smaller scale interactions) were significant. Although not significant, for both habitats, location explained most of the variation in abundance (52\% for seagrass and $48 \%$ for unvegetated sediment) compared to site (location) (5\% for seagrass and 10\% for unvegetated sediment) (Table 4). This suggests that factors operating at both large and small spatial scales influenced trait distributions as indicated by the regression analyses.

For Batillaria australis, there was a significant interaction between habitat and sites within locations only. All other factors and interactions were highly non-significant $(\mathrm{p}>0.170)$. This suggests that body size in B. australis was responding to local scale processes (albeit weakly) rather than those occurring at larger scales (i.e. among locations). For B. australis in seagrass, site (location) accounted for more variation in body size ( $47 \%$ ) than location (27\%) (Table 4$)$. For $B$. australis in unvegetated sediments, variance components at both scales contributed equally to shell size (19\%). The variance components for B. australis shell size were, however, all non-significant (Table 4). 
Table 2. Variance component analyses for the effects of site (nested with location) and location on the abundance of Anadara trapezia and Batillaria australis (ind. $\mathrm{m}^{-2}$ ) in unvegetated sediment and seagrass habitats from 2 sites from multiple locations (5 for $A$. trapezia and 3 for B. australis) on the east coast of Australia. Variance components cannot be calculated for fixed factors, so there is no variance component for habitat. For A. trapezia, variance component analyses were conducted on each habitat separately because of significant interaction terms in the nested ANOVA. Abundance data were log-transformed. $n=15$ quadrats habitat ${ }^{-1}$ site $^{-1}$ species $^{-1}$. Significant effects $(p<0.05)$ are highlighted in bold

\begin{tabular}{|c|c|c|c|c|c|c|c|}
\hline Source & \%Variation & $\begin{array}{c}\text { Variance } \\
\text { components }\end{array}$ & $\mathrm{SE}$ & $Z$ & $\mathrm{p}$ & $\begin{array}{l}95 \% \text { confi } \\
\text { Lower }\end{array}$ & $\begin{array}{l}\text { ce interval } \\
\text { Upper }\end{array}$ \\
\hline \multicolumn{8}{|l|}{ A. trapezia: seagrass } \\
\hline Location & 38 & 0.314 & 0.279 & 1.125 & 0.261 & -0.233 & 0.862 \\
\hline Site (Location) & 15 & 0.124 & 0.095 & 1.312 & 0.189 & -0.061 & 0.311 \\
\hline Error & 47 & 0.382 & 0.045 & 8.367 & $<0.001$ & 0.292 & 0.471 \\
\hline \multicolumn{8}{|l|}{ A. trapezia: sediment } \\
\hline Location & 62 & 0.241 & 0.212 & 1.137 & 0.255 & -0.174 & 0.656 \\
\hline Site (Location) & 21 & 0.078 & 0.069 & 1.122 & 0.261 & -0.058 & 0.213 \\
\hline Error & 17 & 0.474 & 0.057 & 8.367 & $<0.001$ & 0.363 & 0.585 \\
\hline \multicolumn{8}{|l|}{ B. australis } \\
\hline Location & - & $-0.476^{\mathrm{a}}$ & 0.000 & - & - & - & - \\
\hline Site (Location) & 53 & 1.726 & 1.154 & 1.495 & 0.135 & -0.536 & 3.988 \\
\hline Habitat $\times$ Site (Location) & 3 & 0.096 & 0.123 & 0.787 & 0.431 & -0.142 & 0.337 \\
\hline Habitat $\times$ Location & - & $-0.053^{\mathrm{a}}$ & 0.000 & - & - & - & - \\
\hline Error & 44 & 1.445 & 0.158 & 9.165 & 0.000 & 1.140 & 1.760 \\
\hline
\end{tabular}

\section{DISCUSSION}

Spatial scale affected abundance and body size variation in both Anadara trapezia and Batillaria australis. As predicted, patterns in body size and abundance were disconnected. For both species, abiotic variation occurring at large scales (i.e. latitude) best explained patterns in abundance, whereas patterns in body size were best predicted by abiotic factors occurring at smaller spatial scales.

Biogeographic theory suggests that abundance distributions should follow the abundant-centre hypothesis $(\mathrm{ACH})$. Under the $\mathrm{ACH}$, abundance of individual species should be highest in the middle of their geographical distribution and reduced towards the edges (Brown 1984, Hengeveld 1990). For marine invertebrates in coastal intertidal ecosystems, individual species can follow an abundant-centre distribution, although no patterns of increases or decreases in abundance with increasing latitude have concurrently been described (Rivadeneira et al. 2010, Tam \& Scrosati 2011). In our study, Batillaria australis showed evidence of an abundant-centre distribution (although location was not statistically significant in the nested ANOVA). For Anadara trapezia, however, abundance increased with increasing latitude, and was highest at the 2 southernmost sites. This form of
Table 3. Nested ANOVA testing for the effect of the factors location (random), habitat (fixed) and site (nested within location) (random factor) on the shell length (mm) of Anadara trapezia and Batillaria australis in unvegetated sediment and seagrass habitats from 2 sites from multiple locations ( 5 for $A$. trapezia and 3 for $B$. australis) on the east coast of Australia. For $A$. trapezia, $\mathrm{n}=50$ ind. habitat $^{-1}$ site $^{-1}$; for $B$. australis, $\mathrm{n}=18$ to 50 ind. habitat ${ }^{-1}$ site $^{-1}$. Significant effects $(\mathrm{p}<0.05)$ are highlighted in bold

\begin{tabular}{|lrrrr|}
\hline Source & df & \multicolumn{1}{c}{ MS } & $F$ & $\mathrm{p}$ \\
\hline A. trapezia & & & & \\
Habitat & 1 & 8189.89 & 4.488 & 0.102 \\
Site (Location) & 5 & 321.02 & 0.898 & 0.546 \\
Location & 4 & 7382.00 & 4.129 & 0.111 \\
Location $\times$ Habitat & 4 & 1824.69 & 5.102 & 0.052 \\
Habitat $\times$ Site (Location) & 5 & 357.66 & 9.355 & $<\mathbf{0 . 0 0 1}$ \\
Residual & 980 & 38.232 & & \\
Student-Newman-Keuls tests: & & & \\
Seagrass abundance: Location $2=4=6<3=5$ & \\
Sediment abundance: Location & $2=3=4=5=6$ & \\
B. australis & & & & \\
Habitat & 1 & 0.864 & 0.002 & 0.969 \\
Site (Location) & 3 & 1008.59 & 3.375 & 0.172 \\
Location & 2 & 2225.83 & 1.912 & 0.290 \\
Location $\times$ Habitat & 2 & 504.63 & 1.810 & 0.304 \\
Habitat $\times$ Site (Location) & 3 & 298.85 & 19.274 & $<\mathbf{0 . 0 0 1}$ \\
Residual & 440 & 15.505 & & \\
\hline
\end{tabular}


Table 4. Variance component analyses for the effects of site (nested with location) on shell length of Anadara trapezia and Batillaria australis in unvegetated sediment and seagrass habitats from 2 sites from multiple locations (5 for A. trapezia and 3 of $B$. australis) on the east coast of Australia. Variance components cannot be calculated to fixed factors, so there is no variance component for habitat. Variance component analyses were conducted on each habitat separately because of significant interaction terms in the nested ANOVA. For A. trapezia, $\mathrm{n}=50$ ind. habitat ${ }^{-1}$ site $^{-1}$; for $B$. australis, $\mathrm{n}=18$ to $^{2}$ ind. habitat ${ }^{-1}$ site $^{-1}$. Significant effects $(\mathrm{p}<0.05)$ are highlighted in bold

\begin{tabular}{|c|c|c|c|c|c|c|c|}
\hline Source & \%Variation & $\begin{array}{c}\text { Variance } \\
\text { components }\end{array}$ & $\mathrm{SE}$ & $Z$ & $\mathrm{p}$ & $\begin{array}{r}95 \% \text { confi } \\
\text { Lower }\end{array}$ & $\begin{array}{l}\text { nce interval } \\
\text { Upper }\end{array}$ \\
\hline \multicolumn{8}{|c|}{ A. trapezia: seagrass } \\
\hline Location & 52 & 49.513 & 36.986 & 1.341 & 0.180 & -22.879 & 122.104 \\
\hline Site (Location) & 5 & 4.449 & 3.340 & 1.332 & 0.183 & -2.097 & 10.995 \\
\hline Error & 43 & 41.570 & 2.655 & 15.652 & $<0.001$ & 36.365 & 46.776 \\
\hline \multicolumn{8}{|c|}{ A. trapezia: sediment } \\
\hline Location & 48 & 35.668 & 28.275 & 1.261 & 0.207 & -19.750 & 91.085 \\
\hline Site (Location) & 10 & 7.595 & 5.245 & 1.448 & 0.148 & -2.685 & 17.876 \\
\hline Error & 45 & 34.893 & 2.229 & 15.652 & $<0.001$ & 30.524 & 39.262 \\
\hline \multicolumn{8}{|c|}{ B. australis: seagrass } \\
\hline Location & 27 & 18.053 & 34.953 & 0.517 & 0.606 & -50.453 & 86.560 \\
\hline Site (Location) & 47 & 28.999 & 24.097 & 1.203 & 0.229 & -18.230 & 76.229 \\
\hline Error & 24 & 15.233 & 1.483 & 10.271 & $<0.001$ & 12.323 & 18.139 \\
\hline \multicolumn{8}{|c|}{ B. australis: sediment } \\
\hline Location & 19 & 4.732 & 7.629 & 0.620 & 0.535 & -10.221 & 19.686 \\
\hline Site (Location) & 19 & 4.688 & 4.229 & 1.109 & 0.268 & -3.600 & 12.976 \\
\hline Error & 62 & 15.756 & 1.472 & 10.701 & $<0.001$ & 12.870 & 18.642 \\
\hline
\end{tabular}

distribution is commonly linked to topographical barriers that inhibit expansion (Dawson 2001, Waters \& Roy 2003, Hiscock et al. 2004). Fossil records indicate that the distribution of A. trapezia previously extended further south to Tasmania (Edgar 1997, OZCAM 2010). At the end of the last ice age (approx. 14000 yr ago) Tasmania was isolated from mainland Australia by rising sea levels, possibly restricting gene flow and larval connectivity to Tasmanian populations (Ayre et al. 2009). Thus, the distribution of $A$. trapezia may have previously conformed to the $\mathrm{ACH}$.

A disconnect between abundance and body size may occur if each responds independently to environmental conditions acting at different spatial scales. Evidence from this study supports this hypothesis, although disconnection may occur via several different mechanisms. For both species, abiotic conditions likely to vary at small spatial scales (e.g. sediment redox and DO) were the best predictors of body size, but location or latitude were the best predictors of abundance. Location or latitude are proxies for both biotic (e.g. predation, competition) and abiotic variation (e.g. climate) occurring over large spatial scales. Although we did not determine the abundance of predators or competitors, biogeographic patterns of abundance have been related to the abundance of predators (Brown 1984). In addition, in the absence of biotic influences, traits and abun- dance may become disconnected if abiotic effects on traits are sublethal and do not translate into changes in abundance. The negative effects of both low DO and sediment anoxia are likely examples of this. Indeed, abiotic change can have sublethal effects on the life-history traits of Anadara trapezia without affecting abundance, but only up to threshold values of abiotic change (P. E. Gribben unpubl. data). Alternatively, there may be other fitness-related traits that we did not measure that do correlate with abundance. However, shell length (a proxy for body size) is a good indicator of fitness - at least for A. trapezia (Wright \& Gribben 2008, Gribben et al. 2009b).

The strong interactions between habitat and latitude highlight the need to understand how abundance and body size vary among co-occurring habitats over species' distributions, particularly where species are locally abundant in multiple habitat types. However, there were some consistent differences between habitats with latitude: (1) Abundance of both species was generally higher in seagrass compared to unvegetated sediments. This is perhaps not surprising, given the strong facilitative effects habitat-forming species have on species' abundance in all ecosystems (Posey 1988, Crooks 1998, Badano et al. 2006, Wright et al. 2006). Indeed, at local scales, macrophytes are known to provide a surface for colonisation and a refuge from predation for Anadara 
trapezia (Gribben \& Wright 2006, Gribben et al. 2009b). (2) For A. trapezia, the opposite was true for body size: shell length was higher in unvegetated sediments. Reduced size in seagrass is possibly linked to modification of the abiotic environment associated with dense stands of seagrass, e.g. reduced water flow, food availability, sedimentation, and negative effects on physical and chemical sediment properties (Neira et al. 2005, Hacker \& Dethier 2006, Neira et al. 2006, Gribben et al. 2009b). Alternatively, reduced size in seagrass may be partly due to a sampling bias, i.e. larger numbers of small recruits occurring in seagrass compared to unvegetated sediments. However, we specifically targeted large adult clams and did not include small juveniles in our analyses of body size.

Linking variation in body size and abundance to abiotic variation at multiple spatial scales provides a powerful framework for identifying potential mechanisms driving patterns in body size and abundance. Currently there is a focus on understanding how abiotic processes acting at large spatial scales (e.g. climate change) will affect species' distributions; however, the present study demonstrates the need to understand processes acting at multiple spatial scales when interpreting species' abundance and trait distributions. Here we have shown that patterns in body size and abundance can be disconnected from each other and potentially respond differently to spatially distributed abiotic variables. We suggest that concurrent investigations of the body size and abundance of organisms across their distributions, that incorporate multiple spatial scales and abiotic variation across those same spatial scales, are necessary to increase our ability to predict which factors determine body size and abundance, and how these respond to environmental change.

Acknowledgements. The authors thank D. Colgan of the Australian Museum, J. Healy and D. Potter of the Queensland Museum, W. O'Conner, W. Winter and M. Procter from NSW Fisheries and B. Butler and C. Cliff for assisting with preliminarily field investigations. We also thank field volunteers D. Zhang, C. Ross, K. Lloyd, D. Lloyd, E. Lloyd-James and S. Lloyd. This is publication number 73 of the Sydney Institute of Marine Science.

\section{LITERATURE CITED}

Ayre DJ, Minchinton TE, Perrin C (2009) Does life history predict past and current connectivity for rocky intertidal invertebrates across a marine biogeographic barrier? Mol Ecol 18:1887-1903

Badano EI, Jones CG, Cavieres LA, Wright JP (2006) Assessing impacts of ecosystem engineers on community organization: a general approach illustrated by effects of a high-Andean cushion plant. Oikos 115:369-385

- Berge JA, Bjerkeng B, Pettersen O, Schaanning MT, Oxnevad S (2006) Effects of increased sea water concentrations of $\mathrm{CO}_{2}$ on growth of the bivalve Mytilus edulis L. Chemosphere 62:681-687

Bibby R, Cleall-Harding P, Rundle S, Widdicombe S, Spicer $\mathrm{J}$ (2007) Ocean acidification disrupts induced defences in the intertidal gastropod Littorina littorea. Biol Lett 3: 699-701

Brown JH (1984) On the relationship between abundance and distribution of species. Am Nat 124:255-279

Crooks JA (1998) Habitat alteration and community-level effects of an exotic mussel, Musculista senhousia. Mar Ecol Prog Ser 162:137-152

Dawson MN (2001) Phylogeography in coastal marine animals: a solution from California? J Biogeogr 28:723-736

Edgar GJ (1997) Australian marine life: the plants and animals of temperate waters. Reed Books, Sydney

Gilman SE (2005) A test of Brown's Principle in the intertidal limpet Collisella scabra. J Biogeogr 32:1583-1589

Gribben PE, Wright JT (2006) Sublethal effects on reproduction in native fauna: are females more vulnerable to biological invasion? Oecologia 149:352-361

Gribben PE, Byers JE, Clements M, McKenzie LA, Steinberg PD, Wright JT (2009a) Behavioural interactions between ecosystem engineers control community species richness. Ecol Lett 12:1127-1136

Gribben PE, Wright JT, O'Conner WA, Doblin MA, Eyre B, Steinberg PD (2009b) Reduced performance of native infauna following recruitment to a habitat-forming invasive marine alga. Oecologia 158:733-745

> Hacker SD, Dethier MN (2006) Community modification by a grass invader has differing impacts for marine habitats. Oikos 113:279-286

Harley CDG, Hughes AR, Hultgran KM, Miner BG and others (2006) The impacts of climate change in coastal marine ecosystems. Ecol Lett 9:228-241

Hengeveld R (1990) Dynamic biogeography. Cambridge University Press, Cambridge

> Hiscock K, Southward A, Tittley I, Hawkins S (2004) Effects of changing temperature on benthic marine life in Britain and Ireland. Aquat Conserv 14:333-362

Malcolm HA, Smith SD, Jordan A (2009) Using patterns of reef fish assemblages to refine a habitat classification system for marine parks in NSW, Australia. Aquat Conserv 20:1-10

> McGill BJ (2008) Exploring predictions of abundance from body mass using hierarchical comparative approaches. Am Nat 172:88-101

McKinnon JG, Gribben PE, Davis AR, Jolley DF, Wright JT (2009) Differences in soft-sediment macrobenthic assemblages invaded by Caulerpa taxifolia compared to uninvaded habitats. Mar Ecol Prog Ser 380:59-71

> Meiri S, Dayan T (2003) On the validity of Bergmann's rule. J Biogeogr 30:331-351

> Messier J, McGill BJ, Lechowicz MJ (2010) How do traits vary across ecological scales? A case for trait-based ecology. Ecol Lett 13:838-848

> Neira C, Levin LA, Grosholz ED (2005) Benthic macrofaunal communities of three sites in San Francisco Bay invaded by hybrid Spartina, with comparison to uninvaded habitats. Mar Ecol Prog Ser 292:111-126

Neira C, Grosholz ED, Levin LA, Blake R (2006) Mechanisms generating modification of benthos following 
tidal flat invasion by a Spartina hybrid. Ecol Appl 16: 1391-1404

OZCAM (Online Zoological Collections of Australian Musems) (2010) BioMaps. Accessed 5th Feb 2010. http:// ozcam.ala.org.au/

Posey MH (1988) Community changes associated with the spread of an introduced seagrass, Zostera japonica. Ecology 69:974-983

Quinn GP, Keough MJ (2002) Experimental design and data analysis for biologists. Cambridge University Press, Cambridge

Rainer SF, Ivanovici AM, Wadley VA (1979) Effect of reduced salinity on adenylate charge in three estuarine molluscs. Mar Biol 54:91-99

Rangel TF, Alexandre J, Diniz-Filho F, Bini LM (2010) SAM: a comprehensive application for Spatial Analysis in Macroecology. Ecography 33:46-50

Rivadeneira MM, Hernáez P, Antonio Baeza J, Boltaña S and others (2010) Testing the abundant-centre hypothesis using intertidal porcelain crabs along the Chilean coast: linking abundance and life-history variation. J Biogeogr 37:486-498

Sagarin RD, Gaines SD (2002) The 'abundant centre' distribution: to what extent is it a biogeographical rule? Ecol Lett 5:137-147

Sagarin RD, Gaines SD, Gaylord B (2006) Moving beyond assumptions to understand abundance distributions across the ranges of species. Trends Ecol Evol 21:

Editorial responsibility: Omar Defeo,

Montevideo, Uruguay
$524-530$

> Tam J, Scrosati R (2011) Mussel and dogwhelk distribution along the north-west Atlantic coast: testing predictions derived from the abundant-centre model. J Biogeogr 38: 1536-1545

Underwood A (1997) Experiments in ecology: their logical design and interpretation using analysis of variance. Cambridge University Press, Cambridge

Waters JM, Roy MS (2003) Marine biogeography of southern Australia: phylogeographical structure in a temperate sea-star. J Biogeogr 30:1787-1796

> Wright JT, Gribben PE (2008) Predicting the impact of an invasive seaweed on the fitness of native fauna. J Appl Ecol 45:1540-1549

> Wright JP, Jones CG, Beoken B, Shachak M (2006) Predictability of ecosystem engineering effects on species richness across environmental variability and spatial scales. J Ecol 94:815-824

Wright JT, McKenzie LA, Gribben PE (2007) A decline in the density and health of a native bivalve associated with Caulerpa taxifolia invasion. Mar Freshw Res 58:263-277

> Wright JT, Byers JE, Koukoumaftsis LP, Ralph PJ, Gribben PE (2010) Native species behaviour mitigates the impact of habitat-forming invasive seaweed. Oecologia 163: 527-534

Wright JT, Gribben PE, Byers JE, Munro K (2012) Invasive ecosystem engineer selects for different phenotypes of an associated native species. Ecology 93:1262-1268

Submitted: November 8, 2011; Accepted: May 28, 2012

Proofs received from author(s): August 14, 2012 